\title{
WOUND HEALING POTENTIAL OF METHANOL EXTRACT OF SPATHODEA CAMPANULATA STEM BARK FORMULATED INTO A TOPICAL PREPARATION
}

\section{Kwabena Ofori-Kwakye ${ }^{1 *}$, Awo Afi Kwapong ${ }^{1,2}$ and Marcel Tunkumgnen Bayor ${ }^{1}$}

${ }^{1}$ Department of Pharmaceutics, Faculty of Pharmacy and Pharmaceutical Sciences, College of Health Sciences, Kwame Nkrumah University of Science and Technology, Kumasi, Ghana. ${ }^{2}$ University of Ghana School of Pharmacy, College of Health Sciences, University of Ghana, Legon, Ghana.

*E-mail: koforikwakye@yahoo.com; kokwakye.pharm@knust.edu.gh

\begin{abstract}
This study evaluated the wound healing potential of Spathodea campanulata stem bark in Sprague Dawley rats using the excision wound model. The methanol extract contained glycosides, flavonoids and tannins, and was relatively stable when stored at the room temperature for six (6) months. Solvent-free, semi-solid extract of S. campanulata was incorporated into an aqueous cream and applied ( $10 \% \mathrm{w} / \mathrm{w}$ and $20 \% \mathrm{w} / \mathrm{w})$ on excision wounds of thirty two (32) rats. Cicatrin ${ }^{\circledR}$ cream was used as a standard wound healing agent. Prior to the remedial cream application, done later on twice daily, sixteen (16) rats had their wounds infected with Staphylococcus aureus, while in the remaining sixteen the wounds were kept clean. The surface area of the excision wounds was monitored planimetrically every four (4) days until a complete wound closure or healing took place. Excision wounds treated with $20 \% \mathrm{w} / \mathrm{w}$ Spathodea cream and Cicatrin ${ }^{\circledR}$ cream showed a rapid and comparable decrease (p > 0.05 ) in wound size. In uninfected wounds, both $20 \% \mathrm{w} / \mathrm{w}$ Spathodea cream and Cicatrin ${ }^{\circledR}$ cream application resulted in $\sim 95 \%$ wound closure seen on Day 20, and a complete closure seen on Day 24. In infected wounds, both $20 \%$ w/w Spathodea cream and Cicatrin $^{\circledR}$ cream administration led to $\sim 91 \%$-wound closure on Day 24 and a complete wound contraction on Day 28 . The results of this study justify the folkloric use of $S$. campanulata stem bark to the effect of wound treatment.
\end{abstract}

Key words: Spathodea campanulata, wound healing, excision wound model, Spathodea cream, Cicatrin ${ }^{\circledR}$ cream, wound contraction

\section{Introduction}

A wound is described as a break in continuity of tissue arising on the grounds of violence or trauma, and acts as a portal of entry of microbial infective agents into inner tissues. Wound healing as a complex biochemical process, involves the interrelated processes of inflammation, cell proliferation and collagen lattice contraction (Bodeker and Hughes, 1998). Wound healing seeks to replace damaged tissue with a living one, or to regenerate the tissues at wounded or inflamed sites. Wound healing process can be affected by microbial infections and the presence of free oxygen radicals (Houghton et al., 2005). Other factors that may inhibit wound healing include necrotic tissue, diabetes mellitus, lymphatic blockage, certain drugs, and vitamin and mineral deficiencies (Puratchikody et al., 2006; Odimegwu et al., 2008).

Spathodea campanulata P. Beauv. (Bignoniaceae) is a plant species used in folkloric medicine in Ghana and several African countries to the effect of wound healing. Among the Ashanti ethnic group in Ghana, S. campanulata stem bark is applied on wounds by traditional healers in form of a paste (Mensah et al., 2003; Houghton et al., 2005). The plant is widely distributed in Africa, while its stem bark has hypoglycemic, anti-complement, anti-HIV and anti-malarial properties (Amusan et al., 1996; Niyonzima et al., 1999). Antimicrobial and antioxidant properties of S. campanulata significantly contribute to its wound healing potential. We have recently reported that extracts and topical products prepared from S. campanulata stem bark exhibit a broadspectrum antibacterial activity, its methanol extract thereby demonstrating the most superior antibacterial activity of them all (Ofori-Kwakye et al., 2009). Several chemical constituents, to which the wound healing properties of S. campanulata stem bark are ascribed, have been isolated (Ngouela et al., 1988; 1990; Mbosso et al., 2008).

The present study was undertaken in order to evaluate the wound healing potential of S. campanulata stem bark claimed by traditional healers. Semi-solid, solvent-free methanol extract of S. campanulata stem bark was formulated into a topical preparation, applied on excision wounds of experimental rats, and thence evaluated for its wound healing potential. 


\title{
Materials and Methods \\ Harvesting and preparation of the plant material
}

The stem bark of S. campanulata (voucher number FP/FP/SC201303/KOK) was harvested, authenticated, prepared and stored as previously described (Kwapong, 2007; Ofori-Kwakye et al., 2009).

\section{Chemicals and standard drug}

Nutrient agar, emulsifying ointment BP, chlorocresol, sodium hydroxide, hydrochloric acid, methanol, ethanol, acetone, petroleum ether, chloroform and dimethylsulphoxide (DMSO) were obtained from the Chemical store of the Department of Pharmaceutics, Faculty of Pharmacy and Pharmaceutical Sciences, KNUST, Kumasi, Ghana. Cicatrin ${ }^{\circledR}$ antibiotic cream (GlaxoSmithKline, UK), each gram thereby containing 3,300 units of neomycin sulphate, 250 units of bacitracin zinc, $2 \mathrm{mg}$ of Lcysteine, $10 \mathrm{mg}$ of glycine, and $1 \mathrm{mg}$ of dl-threonine, was used as a standard wound healing agent.

\section{Test microorganism}

Gram - positive Staphylococcus aureus NCTC 10788 bacterium was obtained from the stock of the Pharmaceutical Microbiology laboratory, Department of Pharmaceutics, Faculty of Pharmacy \& Pharmaceutical Sciences, KNUST, Ghana. The bacterial strain was grown and maintained on a nutrient agar at $37^{\circ} \mathrm{C}$, while a diluted preparation containing $5 \times 10^{7} \mathrm{~S}$. aureus colony-forming units (cfu)/ml was used for in vivo study.

\begin{abstract}
Animals
Thirty-two (32) Sprague Dawley rats of both sexes (16 of each gender), weighing 225 - $290 \mathrm{~g}$ and obtained from the stall of the Department of Pharmacology, KNUST, Kumasi, Ghana, were used for in vivo study. In order to stabilize prior to the experiment, the animals had been housed under standard environmental conditions, i.e. at the temperature of $31 \pm 1^{\circ} \mathrm{C}$ with $12: 12$ light/dark alteration for 7 days, fed with a standard pellet diet, and given tap water ad libitum. The study was conducted in accordance with the National Institute of Health's Guide for the Care and Use of Laboratory Animals (National Academy Press, 1996) and with approval by the Departmental Ethics Committee.
\end{abstract}

\section{Plant extraction}

About $100 \mathrm{~g}$ of the coarsely milled stem bark of S. campanulata was continuously methanol-extracted using a Soxhlet extraction apparatus for $24 \mathrm{hrs}$. The extract was filtered and concentrated under reduced pressure and the controlled temperature $\left(50-55^{\circ} \mathrm{C}\right)$, so as to achieve dryness and ultimately obtain a solvent-free semi-solid extract.

\section{The effect of storage time on extract's physicochemical properties}

Physical appearance, solubility, $\mathrm{pH}$, absorbance and phyto-chemical content of both freshly prepared and six (6) month-stored S. campanulata methanol extract were determined. The solubility of concentrated semi-solid extract was determined by virtue of vigorous shaking of $0.1 \mathrm{~g}$ of extract in $3 \mathrm{ml}$ of a range of polar and non-polar solvents. Methanol extract's pH-value was tested using a standardized $\mathrm{pH}$-meter. Absorbance of the extracts in reference was determined spectrophotometrically (Cecil CE spectrophotometer, England) at $268 \mathrm{~nm}$ wavelength (Kwapong, 2007). Methanol extract was screened for glycosides, flavonoids, tannins, saponins, coumarins, terpenoids, steroids and alkaloids using the methodology proposed by Harbourne (1998).

\section{Formulation of S. campanulata topical cream}

Aqueous cream BP was prepared using the fusion method (British Pharmacopoeia, 1993). Twenty grams (20 g) of semi-solid S. campanulata methanol extract were incorporated into the aqueous cream by virtue of pestle trituration in a ceramic mortar so as to obtain $100 \mathrm{~g}$ of topical preparation (Spathodea cream) containing $20 \% \mathrm{w} / \mathrm{w}$ of S. campanulata extract. Another batch of Spathodea cream was prepared so as to contain $10 \% \mathrm{w} / \mathrm{w}$ of $S$. campanulata extract. The remedial creams were stored in a refrigerator until used.

\section{Excision wounds}

Wounds were inflicted on thirty-two (32) Sprague Dawley rats in line with the excision wound model. The Sprague Dawley rats were divided into two equal groups (A and B), each group consisting of sixteen (16) rats. Animals assigned to each group were further divided into four subgroups, each subgroup contained four rats. In each group, wound healing effects of $S$. campanulata cream on infected (Group A) and non-infected (Group B) wounds were evaluated. The rats were anaesthetized with 
diethyl ether and had their back skin hairs (dorsal region towards the tail section) shaved with sterilized razor blades. The depilated skin was cleaned using $70 \%$ - ethanol; in further course, a circle having $20 \mathrm{~mm}$ in diameter was marked. A circular incision was made in the marked skin surface area; the skin was thence carefully dissected so as to end up with a wound roughly occupying a $314 \mathrm{~mm}^{2}$-surface (Esimone et al., 2005; Perumal-Samy et al., 2006; Odimegwu et al., 2008). The excision wound area was measured immediately, i.e. traced out using a transparent tracing paper and then counted for a number of squares. The excision wounds inflicted to Group A animals were infected with S. aureus by virtue of in-swabbing of $24 \mathrm{~h}$-bacterial broth culture $\left(5 \times 10^{7} \mathrm{cfu} / \mathrm{ml}\right)$ using a sterile cotton swab (Perumal-Samy et al., 2006). Group B animals were left uninfected. Prior to treatment, the excision wounds of all experimental animals were left untreated for $24 \mathrm{hrs}$ post wounding.

\section{Wound treatment and wound healing measurement}

Throughout the study period, the excision wounds were cleaned with normal saline every morning prior to medication. In each animal group (infected and uninfected), the wounds inflicted to animals constituting each of the four subgroups were treated with Cicatrin ${ }^{\mathbb{B}}$ cream (positive control), $20 \% \mathrm{w} / \mathrm{w}$ S. campanulata cream, $10 \% \mathrm{w} / \mathrm{w}$ S. campanulata cream, and normal saline (negative control), respectively. The remedial creams (or normal saline in case of negative controls) were applied topically twice daily and the wounds were left undressed, i.e. opened to the environment. Change in the wound area was monitored periodically every $4^{\text {th }}$ day. Wound contractions were monitored planimetrically by tracing the wound margin on a graph paper (a transparent paper equipped with a millimeter scale) and calculated as percentage reduction in wounded area size (Mukherjee and Suresh, 2000; Esimone et al., 2005; Perumal-Samy et al., 2006). The Sprague Dawley rats were observed for two (2) weeks post complete wound closure and healing for any observable signs of adverse reactions to Spathodea cream.

\section{Statistical analysis}

Tracings of excision wounds were counted; the latter was supplemented by the surface area estimation. The wound closure surface area was also estimated using Scion image software (Scion Corporation, Frederick, Maryland - USA). Three readings were taken for each excision wound and the results were subsequently averaged. The statistical analysis made use of 2way ANOVA processed using GraphPad Prism 5 (GraphPad Software, San Diego, CA, USA). The results are presented as Mean \pm Standard Deviation (SD) and P value, with the threshold value set at 0.05 . Values of $\mathrm{P}<0.05$ were considered statistically significant.

\section{Results}

Table 1 depicts the solubility of freshly prepared and 6 month-stored S. campanulata stem bark extracts in different solvents. The extract was soluble in water, ethanol (70\%), methanol, DMSO, $1 \mathrm{M}$ sodium hydroxide, and $1 \mathrm{M}$ sodium chloride; poorly soluble in chloroform, petroleum ether and ethanol (96\%); and insoluble in acetone. Extract storage did not affect its solubility in the solvents tested. Table 2 shows the influence of storage time on some physicochemical extract properties. The extract was shown to be acidic and the $\mathrm{pH}$ remained stable throughout storage. The absorbance of the extract, however, slightly changed during storage. Glycosides, flavonoids and tannins were present in fresh and stored extracts, whilst saponins, coumarins, terpenoids, steroids and alkaloids were not detected.

Table 3 shows the effect of $S$. campanulata cream on the contraction of uninfected excision wounds. Wound contraction or closure attained by virtue of $20 \% \mathrm{w} / \mathrm{w}$ S. campanulata cream application was comparable $(\mathrm{p}>0.05)$ to that attained by Cicatrin ${ }^{\circledR}$ cream application. Wound contraction seen with $20 \%$ Spathodea and Cicatrin ${ }^{\circledR}$ cream on Day 20 was 95.50 $\pm 3.24 \%$, and $94.75 \pm 1.95 \%$, respectively, while the ultimate wound contraction or closure was in both cases attained on Day 24. Wound contraction induced by $20 \% \mathrm{w} / \mathrm{w}$ Spathodea cream was not statistically different $(\mathrm{p}>0.05)$ from that seen with $10 \%$ w/w Spathodea cream. In $10 \% \mathrm{w} / \mathrm{w}$ Spathodea cream, a complete wound contraction was achieved on Day 28, as compared to Day 32 in the negative (normal saline-treated) controls. The group of rats whose excision wounds were left uninfected, no clinical signs of infection during and after the study had been revealed.

Table 4 shows the influence of $S$. campanulata cream on the contraction of excision wounds infected with S. aureus. During the study period, the excision wounds in reference appeared pale-red with patches of pus indicating the presence of a clinical infection.. Wound contraction attained by $20 \% \mathrm{w} / \mathrm{w}$ Spathodea cream was comparable $(\mathrm{p}>0.05)$ to that seen with Cicatrin ${ }^{\circledR}$ cream. On Day 24, wound contraction achieved with $20 \% \mathrm{w} / \mathrm{w}$ Spathodea cream was $90.58 \pm 9.55 \%$, as compared to $90.92 \pm 3.53 \%$ seen with Cicatrin ${ }^{\circledR}$ cream. Complete wound contraction or closure occurred on Day 28 both in Cicatrin ${ }^{\circledR}$ and 20 $\% \mathrm{w} / \mathrm{w}$ Spathodea creams. The results obtained by virtue of $10 \% \mathrm{w} / \mathrm{w}$ Spathodea cream and normal saline administration in rats infected with S. aureus, were not statistically reliable as indicated by major standard deviations (Table 4).

\section{Discussion}

The solubility of S. campanulata stem bark methanol extract was determined in acidic, alkaline, polar and non-polar solvents. The extract was soluble in polar solvents and poorly soluble in non-polar solvents, indicating that the extract contains more polar than non-polar components. The stability of the extract was evaluated upon a 6 month-storage at the room 
temperature; on the occasion, $\mathrm{pH}$-value, absorbance and phytochemical content were determined. Upon a 6 month-storage at the room temperature, the extract's $\mathrm{pH}$ value, revealed to be acidic in the first place, remained relatively stable. In our in vitro studies, S. campanulata stem bark extract was found to contain glycosides, flavonoids, and tannins.

Table 1: The influence of storage time on the solubility of concentrated semi-solid extract of S. campanulata stem bark in different solvents

\begin{tabular}{lll}
\hline Solvent & Fresh SC extract & 6month-stored SC extract \\
\hline Water & Soluble & Soluble \\
$1 \mathrm{M} \mathrm{NaOH}$ & Soluble & Soluble \\
$1 \mathrm{M} \mathrm{HCl}$ & Soluble & Soluble \\
Chloroform & Poorly soluble & Slightly soluble \\
Petroleum ether & Poorly soluble & Slightly soluble \\
Ethanol $(96 \%)$ & Poorly soluble & Slightly soluble \\
Ethanol $(70 \%)$ & Soluble & Soluble \\
Methanol & Soluble & Soluble \\
Acetone & Insoluble & Insoluble \\
DMSO & Soluble & Soluble \\
\hline
\end{tabular}

$\mathrm{SC}=$ S. campanulata, $\mathrm{DMSO}=$ dimethylsulphoxide

Table 2: The influence of storage time on some physical and phytochemical properties of S. campanulata stem bark methanol extract

\begin{tabular}{lll}
\hline Parameter & Fresh SC extract & 6 month-stored SC extract \\
\hline Appearance & Coffee brown & Coffee brown \\
pH & $4.58 \pm 0.01$ & $4.57 \pm 0.05$ \\
$*$ Absorbance & $0.57 \pm 0.01$ & $0.52 \pm 0.12$ \\
Glycosides & Present & Present \\
Flavonoids & Present & Present \\
Tannins & Present & Present \\
\hline
\end{tabular}

$* \lambda_{\max }=268 \mathrm{~nm}$, nominal concentration of $S$. campanulata extract used $\sim 0.016 \% \mathrm{w} / \mathrm{v} ; \mathrm{SC}=S$. campanulata

Note: Both fresh and 6 month-stored SC extracts were tested for the presence of other phytochemicals, namely saponins, coumarins, terpenoids, steroids, and alkaloids, but all of the aforementioned tested negative.

Table 3: The effect of $S$. campanulata cream on the contraction of uninfected excision wounds inflicted to Sprague Dawley rats $($ mean $\pm \mathrm{SD}, \mathrm{n}=4)$.

\begin{tabular}{cllll}
\hline \multirow{2}{*}{ Day } & \multicolumn{4}{c}{ Wound contraction (\%) } \\
\cline { 2 - 5 } & Cicatrin ${ }^{\circledR}$ cream & $\begin{array}{l}\text { 20\% } / \text { w Spathodea } \\
\text { campanulata cream }\end{array}$ & $\begin{array}{l}10 \% \text { w } / \text { Spathodea } \\
\text { campanulata cream }\end{array}$ & Normal saline \\
\hline 4 & $20.17 \pm 4.81$ & $32.75 \pm 15.52$ & $21.58 \pm 8.19$ & $20.00 \pm 3.66$ \\
8 & $44.33 \pm 17.57$ & $62.83 \pm 3.45$ & $62.75 \pm 7.71$ & $36.00 \pm 6.90$ \\
12 & $80.67 \pm 3.50$ & $87.17 \pm 2.78$ & $83.58 \pm 6.84$ & $44.00 \pm 31.45^{* *}$ \\
16 & $86.50 \pm 4.67$ & $91.33 \pm 4.50$ & $85.83 \pm 1.40$ & $68.33 \pm 45.60$ \\
20 & $94.75 \pm 1.95$ & $95.50 \pm 3.24$ & $88.75 \pm 3.51$ & $69.58 \pm 46.44$ \\
24 & $100.00 \pm 1.05$ & $100.00 \pm 0.80$ & $93.50 \pm 3.18$ & $71.83 \pm 47.89^{*}$ \\
28 & Healed & Healed & Healed & $72.58 \pm 48.39$ \\
32 & Healed & Healed & Healed & Healed \\
\hline
\end{tabular}

*P $<0.05, * * \mathrm{P}<0.01$ when compared to Cicatrin ${ }^{\mathbb{B}}$ cream (positive control) and $20 \% \mathrm{w} / \mathrm{w}$ Spathodea campanulata cream, Normal saline $=$ negative control, Healed $=100 \%$ wound contraction or closure

This confirms earlier reports on S. campanulata stem bark methanol extract content (Ngouela et al., 1990; Tsuchyia et al., 1996). No qualitative effects of extract storage on phytochemicals present therein had been revealed; however, possible quantitative effects could not be established. The tested extract did not contain phytochemicals such as saponins, coumarins, terpenoids, steroids, and alkaloids. Upon a 6 month-storage at the room temperature, the change in extract's absorbance properties $(p>0.05)$ was only slight. This means that storage induces only slight or no changes in extract's chemical composition. On the whole, 6 month-storage of S. campanulata extract at the room temperature had no significant effect on its physicochemical properties. The stability of the extract would minimize any physical or chemical breakdown which may affect its activity when stored for a longer period of time. 
Wound healing is a complex and dynamic process of restoring cellular structures and tissue layers in damaged tissues to their normal state as closely as possible. In the current study, in vivo wound healing potential of S. campanulata stem bark-based cream was established in Sprague Dawley rats of both sexes using the excision wound model.

Table 4: The effect of S. campanulata cream on the contraction of excision wounds of Sprague Dawley rats infected with $S$. aureus (mean $\pm \mathrm{SD}, \mathrm{n}=4$ )

\begin{tabular}{|c|c|c|c|c|}
\hline \multirow{2}{*}{ Day } & \multicolumn{4}{|c|}{ Wound contraction $(\%)$} \\
\hline & Cicatrin $^{(\mathbb{R}}$ cream & $\begin{array}{l}20 \% \text { w/w Spathodea } \\
\text { campanulata cream }\end{array}$ & $\begin{array}{l}10 \% \text { w/w Spathodea } \\
\text { campanulata cream }\end{array}$ & Normal saline \\
\hline 4 & $31.50 \pm 10.15$ & $15.17 \pm 4.84$ & $15.25 \pm 11.74$ & $12.83 \pm 5.23$ \\
\hline 8 & $44.08 \pm 2.27$ & $34.92 \pm 11.67$ & $17.83 \pm 20.76$ & $35.50 \pm 14.56$ \\
\hline 12 & $66.83 \pm 3.72$ & $56.67 \pm 22.10$ & $18.92 \pm 28.31 * *$ & $43.25 \pm 21.74$ \\
\hline 16 & $74.75 \pm 2.89$ & $70.17 \pm 15.74$ & $31.92 \pm 28.75^{*}$ & $53.17 \pm 15.15$ \\
\hline 20 & $87.08 \pm 1.10$ & $91.42 \pm 7.33$ & $\mathrm{~b} 44.83 \pm 28.68^{*}$ & $61.17 \pm 19.16$ \\
\hline 24 & $90.92 \pm 3.53$ & $90.58 \pm 9.55$ & $66.00 \pm 10.53$ & $73.25 \pm 17.77$ \\
\hline 28 & $100.00 \pm 1.95$ & $100.00 \pm 2.55$ & a $59.75 \pm 40.06^{*}$ & $84.33 \pm 10.84$ \\
\hline 32 & Healed & Healed & $61.50 \pm 42.93$ & $62.08 \pm 41.74$ \\
\hline 36 & Healed & Healed & $69.83 \pm 47.01$ & $64.50 \pm 44.11$ \\
\hline 40 & Healed & Healed & $73.00 \pm 48.81$ & $64.67 \pm 44.39$ \\
\hline 44 & Healed & Healed & $71.42 \pm 47.83$ & $71.08 \pm 47.59$ \\
\hline 48 & Healed & Healed & ${ }^{\mathrm{b}} 50.00 \pm 57.74 * *$ & $100.01 \pm 25.70$ \\
\hline
\end{tabular}

${ }^{*} \mathrm{P}<0.05,{ }^{* *} \mathrm{P}<0.01$, when compared to Cicatrin ${ }^{(B)}$ cream (positive control), ${ }^{\mathrm{a}} \mathrm{P}<0.05,{ }^{\mathrm{b}} \mathrm{P}<0.01$ when compared to $20 \%$ w/w Spathodea campanulata cream, Normal saline $=$ negative control, Healed $=100 \%$ wound contraction or closure

The excision wounds were left untreated for 24 hours before treatment so as to allow for the S. aureus infection to take root. Wound contraction, which is a part of the end-stage wound-healing process, was measured and used as an index of the extract's wound healing potential. Wounds naturally heal dependent on the presence or absence of wound infection. Excision wounds infected with $S$. aureus took a longer time to contract and heal than the uninfected ones due to the fact that wound infection leads to the formation of microbial toxins and exudates implicated in regenerating cells'killing (Houghton et al., 2005). In both infected and uninfected excision wounds, wound contraction or healing process was accelerated by the application of $S$. campanulata topical preparations. Wound-healing effect exhibited by $20 \% \mathrm{w} / \mathrm{w}$ Spathodea cream was slightly more pronounced $(\mathrm{p}>0.05)$ than that of $10 \% \mathrm{w} / \mathrm{w}$ Spathodea cream. Wound healing potential of $20 \% \mathrm{w} / \mathrm{w}$ Spathodea cream was comparable $(\mathrm{p}>$ $0.05)$ to that of Cicatrin ${ }^{\circledR}$ cream, acknowledged as a standard antibacterial cream used to the effect of wound healing.

Different physiological processes known to be associated with wound healing include anti-inflammatory action, fibroblast proliferation, effect on keratinocytes, fibroblast protein expression, collagen lattice formation, antimicrobial activity, and antioxidant properties (Houghton et al., 2005). In order to offer scientific proof of, and justification for, their traditional use as wound-healing agents, plant-based topical remedies should exhibit multiple effects on these wound healing-related physiological processes. The current study provided ample evidence of wound healing potential of $S$. campanulata stem bark extract in terms of improving the rate of wound contraction and healing in both infected and uninfected experimental rats. The wound healing potential of $S$. campanulata stem bark could be attributed to the presence of phytochemicals such as glycosides, flavonoids, and tannins. Some of these phyto-constituents are known to demonstrate various antimicrobial and antioxidant 
properties. The antimicrobial effect exhibited by the extract prevents the formation of microbial toxins which tend to inhibit cell regeneration, while its antioxidant action removes excess proteases and reactive oxygen species from the wounds and protect protease inhibitors from oxidative damage (Houghton et al., 2005). Flavonoids present in methanol extract of S. campanulata stem bark are known to reduce peroxidation by preventing or slowing down the onset of cell necrosis, as well as by improving vascularity. Flavonoids and tannins also promote wound healing, mainly due to their astringent and antimicrobial properties, which seem to be responsible for wound contraction and an increased rate of epithelization achieved by $S$. campanulata administration (Tsuchyia et al, 1996). The effect of $S$. campanulata stem bark extract, manifested in experimental rats in an accelerated rate of wound contraction and healing, provides a scientific basis in support of traditional use of $S$. campanulata stem bark to the effect of wound healing.

\section{Conclusions}

Methanol extract of $S$. campanulata stem bark contains glycosides, flavonoids and tannins, but no saponins, coumarins, terpenoids, steroids, and alkaloids. The extract was relatively stable when stored at the room temperature for 6 months. In experimental rats, $20 \% \mathrm{w} / \mathrm{w}$ S. campanulata cream exhibited a substantial wound healing potential comparable to that of Cicatrin $^{\circledR}$ cream, i.e. a standard antibiotic used for wound healing. The findings of this study justify the use of $S$. campanulata stem bark as a wound-healing agent recognized by folkloric medicine.

\section{Acknowledgements}

We wish to acknowledge the technical assistance of Messrs Charles Manful, George Boateng, Francis K. Addai Acheampong (Department of Pharmaceutics), and Thomas Ansah (Department of Pharmacology), Faculty of Pharmacy \& Pharmaceutical Sciences, KNUST, Kumasi, Ghana.

\section{References}

1. Amusan, O. O. G., Adesogan, E. K., Makinde, J. M. (1996). Antimalarial active principles of Spathodea campanulata stem bark. Phytother Res, 10 (8): 692 - 693.

2. Bodeker, G., Hughes, M. A. (1998). Wound healing, traditional treatments and research policy. In: Prendergast, H. D. V., Etkin, N. L., Harris, D. R., Houghton, P. J. (Eds.), Plants for Food and Medicine. Royal Botanic Gardens, Kew, London, pp. 345 - 359.

3. British Pharmacopoeia (1993). Vol. II, British Pharmacopoeia Commission, HMSO Publication Centre, London.

4. Esimone, C. O., Ibezim E. C., Chah, K. F. (2005). The wound healing effect of herbal ointments formulated with Napoleona imperialis. J. Pharmaceut Allied Sci, 3 (1): 294 - 299.

5. Harbourne, J. B. (1998). Phytochemical methods: a guide to modern technique of plant analysis, $2^{\text {nd }}$ Ed., Chapman and Hall, London, p. 282.

6. Houghton, P. J., Hylands, P. J., Mensah, A. Y. (2005). In vitro tests and ethnopharmacological investigations: wound healing as an example. J. Ethnopharmacol, 100: 100 - 107.

7. Kwapong, A. A. (2007). Formulation of a topical product from the stem bark of Spathodea campanulata for wound healing. MPharm Thesis. Kwame Nkrumah University of Science and Technology, Kumasi, Ghana pp. 110.

8. Mbosso, E. J., Ngouela, S., Ngudia, J. C., Penlap, V., Rohmer, M., Tsamo, E. (2008). Spathoside, a cerebroside and other antibacterial constituents of the stem bark of Spathodea campanulata. Nat Prod Res, 22 (4): $296-304$

9. Mensah, A. Y., Houghton, P. J., Fleischer, T. C., Adu, F., Agyare, C., Ameade, A. E. (2003). Antimicrobial and antioxidant properties of two Ghanaian plants used traditionally for wound healing. J. Pharm Pharmacol, 55 (Supplement): S-4.

10. Mukherjee, P. K., Suresh, B. (2000). The evaluation of wound healing potential of Hypericum hookerianum leaf and stem extracts. J. Alternative Compl Med, 6 (1): $61-69$.

11. Ngouela, S., Nyasse, B., Tsamo, E., Sondengam, B. L., Connolly, J. D. (1988). Oleanolic acid from the stem bark of Spathodea campanulata. Planta Med, 54: 476.

12. Ngouela, S., Nyasse, B., Tsamo, E., Sondengam, B. L., Connolly, J. D. (1990). Spathodic acid, triterpine and sitosterol from the stem bark of Spathodea campanulata. Phytochem, 29 (12): 3959 - 3961.

13. Niyonzima, G., Laekeman, G., Witvrouw, M., Van Poel, B., Pieters, L., Paper, D., De Clercq, E., Franz, G., Vlietinck, A. J. (1999). Hypoglycemic, anticomplement and anti-HIV activities of Spathodea campanulata stem bark. Phytomed, 6 (1): 45 - 49.

14. Odimegwu, D. C., Ibezim, E. C., Esimone, C. O., Nworu, C. S., Okoye, F. B. C. (2008). Wound healing and antibacterial activities of the extract of Dissotis theifolia (Melastomataceae) stem formulated in a simple ointment base. J. Med Plant Res, 2(1): $011-016$.

15. Ofori-Kwakye, K., Kwapong, A. A., Adu, F. (2009). Antimicrobial activity of extracts and topical products of the stem bark of Spathodea campanulata for wound healing. Afr J Tradit Complement Altern Med, 6 (2): 168 - 174.

16. Perumal-Samy, R., Gopalakrishnakone, P., Sarumathi, M., Ignacimuthu, S. (2006). Wound healing potential of Tragia involucrata extract in rats. Fitoter, 77 (4): 300 - 302.

17. Puratchikody, A., Devi, C. N., Nagalakshmi, G. (2006). Wound healing activity of Cyperus rotundus linn. Indian J. Pharm Sci, 68 (1): $97-101$.

18. Tsuchyia, H., Sato, M., Miyazaki, T., Fujiwara, S., Tanigaki, S., Ohyama, M., Tanka, T., Linuma, M. (1996). Comparative study on the antibacterial activity of phytochemical flavanones against methicillin-resistant Staphylococcus aureus. J. Ethnopharmacol, 50: 27 -34 . 